\title{
Calcifying vascular smooth muscle cells and osteoblasts: independent cell types exhibiting extracellular matrix and biomineralization-related mimicries
}

Rodrigo DAM Alves, Marco Eijken, Jeroen van de Peppel and Johannes PTM van Leeuwen*

\begin{abstract}
Background: Ectopic vascular calcifications represent a major clinical problem associated with cardiovascular disease and mortality. However, the mechanisms underlying pathological vascular calcifications are largely unknown hampering the development of therapies to tackle this life threatening medical condition.

Results: In order to gain insight into the genes and mechanisms driving this pathological calcification process we analyzed the transcriptional profile of calcifying vascular smooth muscle cells (C-VSMCs). These profiles were compared to differentiating osteoblasts, cells that constitute their physiological calcification counterparts in the body. Overall the transcriptional program of C-VSMC and osteoblasts did not overlap. Several genes, some of them relevant for bone formation, were distinctly modulated by C-VSMCs which did not necessarily lose their smooth muscle cell markers while calcifying. Bioinformatics gene clustering and correlation analysis disclosed limited bone-related mechanisms being shared by two cell types. Extracellular matrix (ECM) and biomineralization genes represented common denominators between pathological vascular and physiological bone calcifications. These genes constitute the strongest link between these cells and represent potential drivers for their shared end-point phenotype.

Conclusions: The analyses support the hypothesis that VSMC trans-differentiate into C-VSMCs keeping their own identity while using mechanisms that osteoblasts use to mineralize. The data provide novel insights into groups of genes and biological processes shared in MSC and VSMC osteogenic differentiation. The distinct gene regulation between C-VSMC and osteoblasts might hold clues to find cell-specific pathway modulations, opening the possibility to tackle undesired vascular calcifications without disturbing physiologic bone formation and vice versa.
\end{abstract}

Keywords: Calcifying, Vascular smooth muscle cells, Osteoblasts, Gene expression, Extracellular matrix, Biomineralization

\section{Background}

Vascular calcification in the tunica media of arteries and blood vessels is often observed in the elderly population, in patients with diabetes mellitus and/or chronic kidney disease [1]. Vascular calcifications represent a major clinical problem being in the origin of cardiovascular disease and ultimately mortality [2]. Vascular smooth muscle cells (VSMCs) are contractile cells located at the medial layer of the vessel wall. VSMCs can be triggered to transdifferentiate into calcified vascular cells (C-VSMCs), loosing the

\footnotetext{
* Correspondence: j.vanleeuwen@erasmusmc.nl

Department of Internal Medicine, Erasmus MC, Wytemaweg 80, 3015 CN Rotterdam, The Netherlands
}

phenotypic markers responsible for smooth muscle cell contractility [3,4]. Further physiological alterations of VSMC include entering a synthetic state with abundant production of extracellular matrix (ECM) proteins [1] followed by matrix vesicle-mediated calcification $[5,6]$.

It has been hypothesized that pathological medial calcification is a process analogue to bone mineralization with VSMCs entering an osteoblast-like differentiation program [7]. Atherosclerotic plaques, of medial and valvular origin, express several bone-related ECM proteins, including osteopontin, collagen I, matrix GLA protein (MGP), osteonectin and osteocalcin [7-9]. In addition, 
calcified vascular tissue expresses bone specific transcription factors and bone morphogenetic proteins (BMPs) [10-13]. Despite these similarities with osteoblast differentiation the exact mechanism behind VSMCs transdifferentiation into C-VSMCs remains largely unknown. Some studies have suggested that only a subset of the VSMC pool has osteogenic potential [10,14]. Pathological vascular calcifications may arise due to loss of mineralization inhibitors, which are continuously expressed in healthy vascular tissue [15]. Mice lacking MGP show spontaneous vascular calcifications [8], a phenotype that is exacerbated when SPP1, another mineralization inhibitor, is deleted [16]. Murshed and colleagues [17] have explored this hypothesis further showing that mineralization can occur in any collagen type I rich tissue that expresses pyrophosphatases such as alkaline phosphatase (ALP). While collagen type I is ubiquitously expressed in the tissues, the co-expression of this ECM protein with ALP is restricted to those that mineralize. ALP is involved in the cleavage of pyrophosphate a potent mineralization inhibitor [18]. This enzyme on its own was shown to be able of inducing calcification in rat models of medial calcification [19]. Normally VSMCs do not express ALP but for unclear reasons they can transdifferentiate into C-VSMCs that show increased ALP activity $[6,20]$.

In this study we aimed to reveal the processes whereby VSMCs develop into C-VSMCs exhibiting a calcified phenotype. We compared this pathological process to the physiological mechanism regarded as an analogue process, the differentiation of mesenchymal stem cells into osteoblasts.

Under consideration were three hypotheses, 1) C-VSMCs are osteoblast or osteoblast-like cells transdifferentiating from the VSMC pool, 2) C-VSMCs initiate mineralization using osteoblast-like mechanisms, and 3) C-VSMCs mineralize using mechanisms unrelated to osteoblasts. To address these hypotheses we used genome-wide gene expression analysis during in vitro human VSMC development into C-VSMCs and human mesenchymal stem cell (MSC) differentiation into osteoblasts. We investigated these processes in terms of their known specific markers but also in an unbiased general perspective, using bioinformatics tools. Global expression profiles and gene regulation were used to pinpoint the transcriptional program and the identity of a C-VSMC in comparison to the phenotype-resembling osteoblast.

\section{Results}

The complete VSMC population develops into an ALP positive population under osteogenic stimuli

VSMCs and MSCs were cultured in osteogenic medium for 25 days to induce development into C-VSMCs and osteoblast respectively. During this period total ALP activity was measured. As shown in Figure 1A, ALP activity increased in C-VSMCs and osteoblasts cultures compared to their precursor cells with enzymatic activity reaching higher absolute levels in osteoblasts than in their CVSMC counterparts.

In addition, we measured ALP expression at the individual cell level by flow cytometry. This data (Figure 1C) corroborated the ALP activity measurements. Furthermore it demonstrates that MSC and VSMC (trans) differentiation is characterized by an expansion of the ALP + cell pool (Figure 1D and E).

\section{C-VSMCs and osteoblasts have distinct global gene expression profiles}

Next, we performed comparative genome-wide mRNA expression analysis in osteogenic VSMC and MSC cultures to characterize their transcriptional similarities and dissimilarities. Five time-points (day 0, 2, 8, 12 and 25) were analyzed during VSMC development to C-VSMCs and MSC to osteoblasts. The data were normalized and probes/genes expressed in neither VSMC/C-VSMC nor $\mathrm{MSC} /$ osteoblasts were excluded from further analysis. The overlap of expressed probes between osteogenic VSMC and MSC cultures contained 14733 probes representing 11302 unique genes. These probes/genes were subsequently used for Principle Component Analysis (PCA). PCA allowed simultaneous comparison of multiple timepoints in both cell types summarizing the relationship between them. The closer the data points appear in the PCA plot (Figure 2), the more similar their gene expression profiles are. The PCA plot showed that VSMCs and MSCs at the start of culture (day 0 ) represented two clearly distinct clusters that upon osteogenic stimulation did not converge into an indistinguishable cluster of similarity (Figure 2). In other words, C-VSMCs and osteoblasts are two distinct cell types in terms of global gene expression.

Several clusters could be identified during C-VSMC and osteoblast development. For both cell types, day 2 represented an intermediate stage after the osteogenic stimuli given to VSMCs and MSCs (day 0; Figure 2). This transient stage is followed by a more stable period, day 8-25, in which gene expression did not change so dramatically (Figure 2).

\section{VSMC calcifications are not dependent on the} down-regulation of smooth muscle cell contractile markers In the subsequent analysis we investigated the expression of (vascular) smooth muscle cell marker genes. We selected established VSMC markers described in literature [21], including alpha-actin-2 (ACTA2), smooth-muscle myosin (MYH11), calponin (CNN1), smooth muscle protein 22-alpha (TAGLN), telokin (MYLK), smoothelin (SMTN), caldesmon (CALD1), vinculin (VCL) and adipocyte enhancer-binding protein 1 (AEBP1) (Figure 3). 


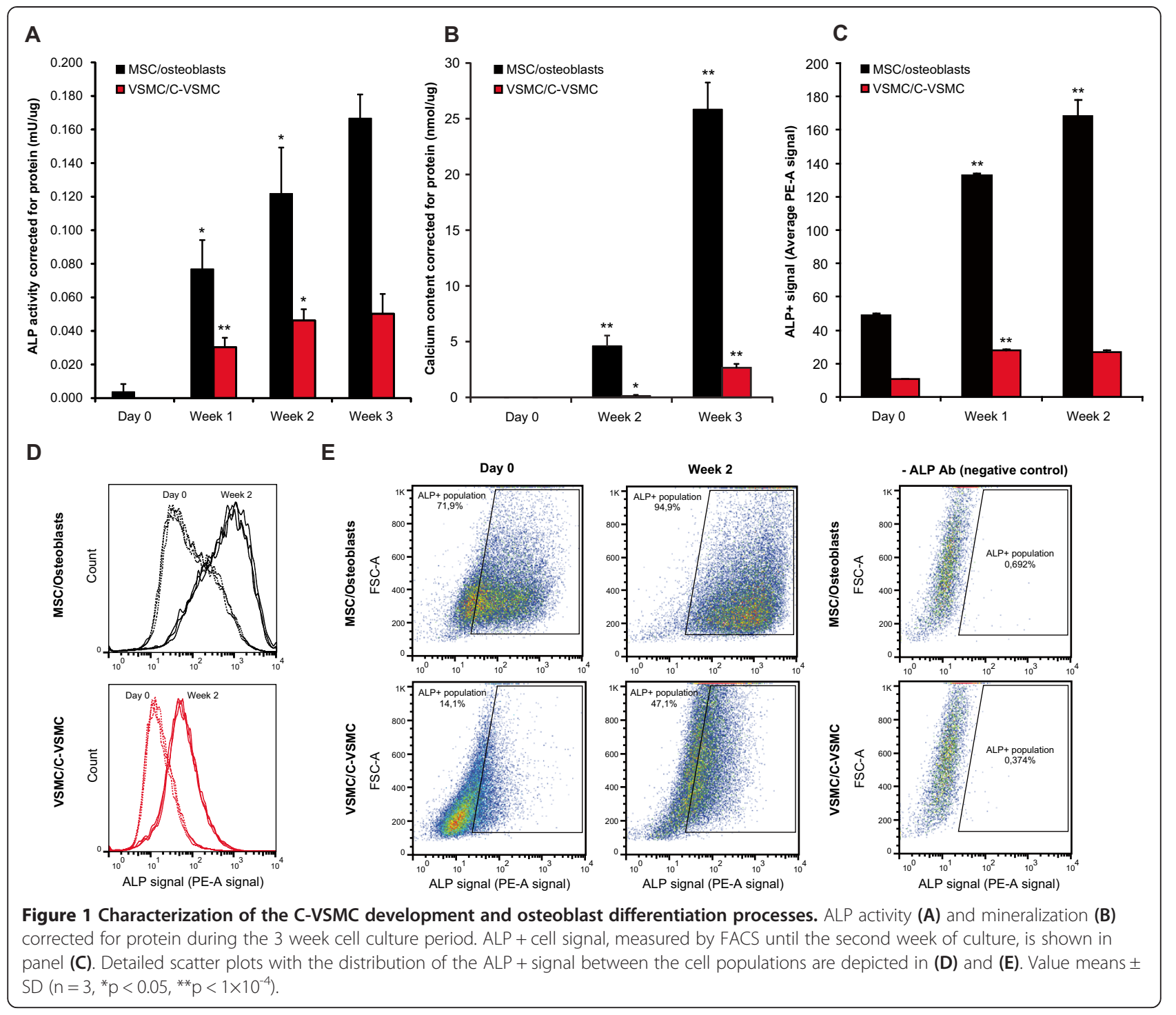

We verified that expression of many of these genes was increased in C-VSMCs compared to their VSMC precursors during osteogenic conditions. This result was confirmed by qPCR but it could not be replicated in C-VSMCs from a second independent donor (Additional file 1: Figure S3). This data demonstrate that C-VSMC are able to transdifferentiate without losing the contractile phenotype markers of VSMC. In addition it raises the idea C-VSMC do not necessarily acquire a full osteoblast-like transcriptome, something also found to be true for other models of vascular calcification [22].

\section{Genes identically regulated by C-VSMCs and osteoblasts} are functionally annotated to extracellular region

To identify whether only specific groups of genes were identically regulated by C-VSMCs and osteoblasts, we have selected differentially expressed genes during VSMC development into C-VSMCs and during MSC differentiation into osteoblasts. Differential expression was calculated for each cell type relative to day 0 , when osteogenic treatment was initiated. Probes/genes were considered differentially expressed when on at least one day during culture their $\log _{2}$ fold-change compared to day 0 was significantly (q-value $<0.001$ ) higher than 0.5 (up-regulation) or lower than -0.5 (down-regulation). During C-VSMC development and osteoblast differentiation 3721 probes and 3114 probes met this criterion, respectively. Considering the two cell types combined, 4782 probes were found to be differentially expressed (Additional file 2: Table S1). Of these 4782 probes, 1638 and 1061 were exclusively differentially expressed in C-VSMCs or in osteoblasts, respectively. Regarding the direction of gene expression regulation, 1968 probes were identically regulated while 150 were oppositely changed during C-VSMC and osteoblast development (Additional file 2: Table S1). 


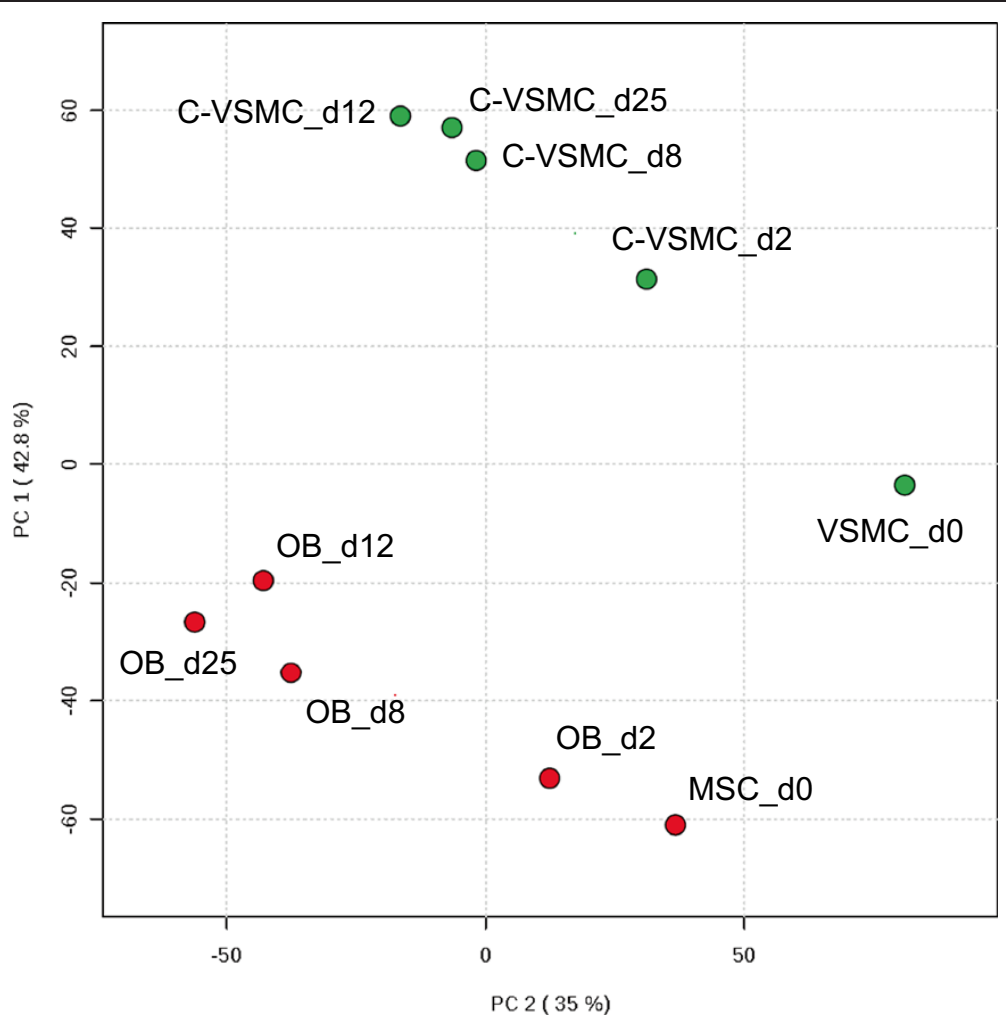

Figure 2 Principal Component Analysis of the global gene expression changes occurring during C-VSMC development and osteoblast differentiation. 14733 probes expressed by both VSMC/C-VSMC and MSC/osteoblasts (OB) at day 0, 2, 8, 12 and 25 were considered for analysis. Distance between samples is directly proportional to gene expression differences. Each time point is represented by the average of 3 biological replicates with exception for day 0 where $n=4$. Between parenthesis in the $x$ - and $y$-axis is the percentage of variance captured by the two principal components.

The temporal and directional expression dynamics of the 4782 differential expressed probes during C-VSMC development and osteoblast differentiation is resumed in Figure 4. K-means clustering separated the differentially expressed probes during C-VSMC development and osteoblast differentiation into clusters sharing common regulation patterns. On basis of Figure of Merit (FOM) analysis we concluded to divide gene expression data in 6 clusters (Figure 4A). This number of clusters was found to provide good predictive power for the k-means algorithm (Additional file 3: Figure S1) without restricting the cluster size for functional annotation analysis. Functional Gene Ontology (GO) annotation of genes underlying these clusters revealed information about the biological processes, cellular compartments and molecular functions during C-VSMC development and osteoblast differentiation (Figure 4B).

Clusters 1, 2 and 3 contained up-regulated genes while clusters 4, 5 and 6 represented down-regulated genes in both C-VSMCs and osteoblasts (Figure 4A). In clusters 1 and 2 C-VSMCs and osteoblast shared the overrepresentation of genes linked to extracellular region (GO:0044421 and GO:0005576, Figure 4B). In clusters
3, 4, and 5 several GO-terms were also shared by CVSMCs and osteoblasts but these were more general GO-terms like cell cycle, RNA processing, chromosome, biological response to organic substance, etc., related to general cell function/metabolism. An exemption was cluster 6 that only showed significant enriched GO terms for C-VSMCs. This fact may be attributed to statistical issues related to the lower number of genes fitting this cluster in osteoblasts. Overall, cluster analyses did not clearly identify sets of bone-related processes or cellular components shared by C-VSMCs and osteoblast. Nevertheless, it was interesting to observe that a common set of extracellular region genes from cluster 1 and 2 (Figure 4A and B) was similarly regulated by both cell types indicating a shared mechanism involving changes in the extracellular environment/matrix.

\section{C-VSMCs express a subset of extracellular matrix genes and genes involved in biomineralization}

Considering the relevance of the extracellular environment for osteoblast differentiation and mineralization, we analysed in greater detail the expression of genes linked to extracellular region present in cluster 1 and 2. Cluster 1 


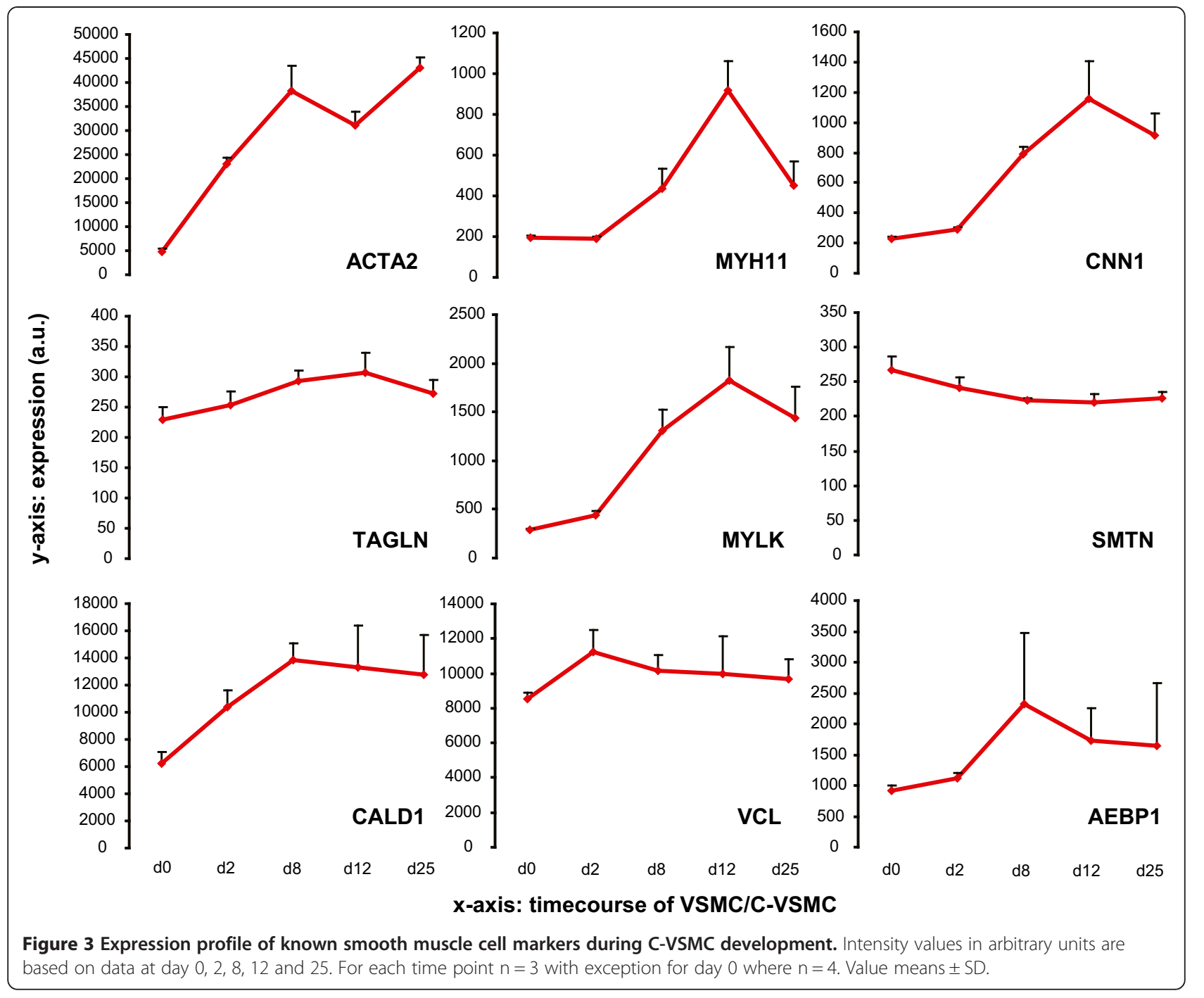

and 2 contained in total 58 extracellular region genes (equivalent to 76 probes; Additional file 4: Table S2) overlapping in C-VSMC and osteoblasts (Figure 5A). Expression pattern analyses of the cell type-specific genes from cluster 1 and 2 (43 and 42 for C-VSMCs and osteoblasts respectively; Additional file 4: Table S2) showed clearly distinct expression patterns for C-VSMCs (Figure 5B) and osteoblasts (Figure 5C).

The observation that among the 58 extracellular region genes overlapping in C-VSMCs and osteoblasts was a large subpopulation of ECM genes prompt us to identify differentially expressed ECM genes (GO:0031012) identically modulated in both cell types. From the 126 (160 probes) differentially expressed ECM genes in total 57 (76 probes) were identically modulated in C-VSMCs and osteoblasts (Additional file 5: Table S3). The expression pattern of these 57 genes is shown in Figure 5D. Some of them are known to be involved in mineralization process of both the bone and the vasculature. This is the case for POSTN (periostin) and ADAMTS1 (ADAM metallopeptidase with thrombospondin type 1 motif), two genes showing consistent regulation across distinct primary cell donors (Additional file 1: Figure S3).

In an alternative approach to compare osteoblasts and $\mathrm{C}$-VSMC we performed gene correlation analyses based on a priori selected GO-terms that are relevant for bone formation and mineralization. These GO-terms included among others biomineral tissue development, osteoblast differentiation and regulation of BMP signaling genes (see the full list of GO-terms analyzed in the Material and Methods section 2.7). To assess specificity, correlation analyses were also performed for a randomly selected set of expressed genes. Genes involved in biomineral tissue development (25 genes; Additional file 6: Table S4) showed the highest correlation between C-VSMCs and osteoblasts $\left(r^{2}=0.31\right.$; Figure $\left.6 \mathrm{~A}\right)$ with an $\mathrm{r}^{2}$ much higher than for a similar number of randomly selected expressed genes $\left(r^{2}=-0.29\right.$; Figure $\left.6 E\right)$. On the 
A

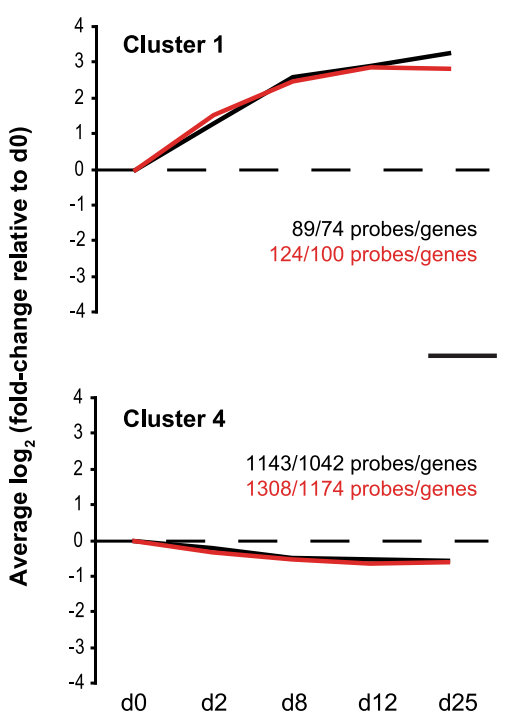

B

\section{Gene Ontology term}

GO:0009719 response to endogenous stimulu
GO:0010033 response to organic substance

G0:0042127 regulation of cell proliforation

GO:0050727 regulatition of inflammatory response
G:00055114 oxidation reduction

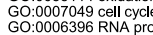

GO:0000278 mitotoic cell cycle

GO:0006412 translation

GO:0016071 mRNA metabolic process

GO::0000280 nuclear division
GO:0051340 regulation of ligase activity

containing compound transport

GO:0006403 RNA localization
GO:0031396 regulation of protein ubiquitination

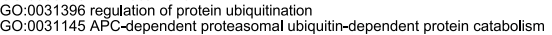

GO:00069913 nucleocytoplasmic transport

GO:0065003 macromolecular complex assembly

60:00075059 chromosome segregation
GO:0051352 neagative requalition of igase activity

G0:0016012 rR rNA metabolic process

GO:0051028 mRNA transport

GO:0007017 microtubule-based process
GO:0010605 negative regulation of macromolecule metabolic process

GO:0000283 3 negallive regut

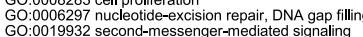

G: 019932 second-messenger-ment

GO:0005576 extracellular region

G0:00005764 Iysossome

GO:0005770 late endoso

60:00005783 endoplasmic reticulum

GO:0005739 mitochondrion

GO:0005794 Golgi apparatus

GO:0031974 membrane-enclosed lumen

GO:00043228 non-membrane-bounded organelle

G0.0005694 chromosome

G0:0000502 proteasome complex

60:0044429 mitochondrial part

G0:0030532 small nuclear ribonucleoprotein complex

GO:00056930 nuclear envelope

GO:0015630 microtubule cytoskeleton
GO:00505732 small nuclealar ribonucleoprotein complex
GO:

GO:0030530 heterogeneous nuclear ribonuclooprotein complex

GO:0015585 chromatin remodeling complex

GO:0005663 DNA replication factor $\mathrm{C}$ complex

GO:0001871 pattern binding

GO:0005533 glycosaminoglycan binding

G0:0008092 cytoskeletal protin binding

GO::0003779 actin binding

GO:0003723 RNA binding

60:0000166 nucleotide binding

:0:0003735 Structural constituent of ribosom

GO:0003697 single-stranct
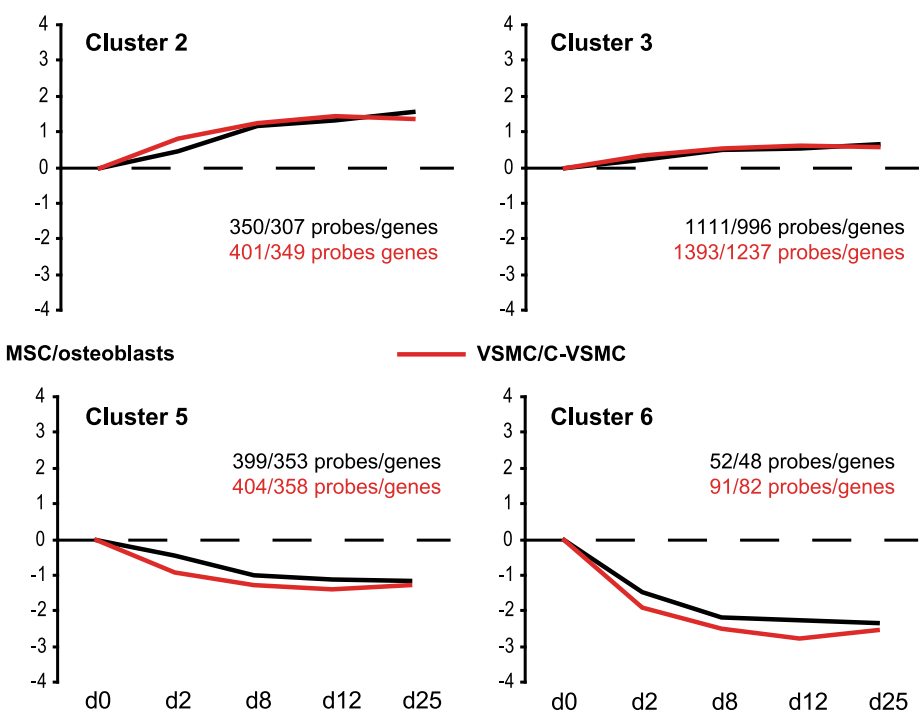

$\begin{array}{llllll}\text { Cluster } 1 & \text { Cluster } 2 & \text { Cluster } 3 & \text { Cluster } 4 & \text { Cluster } 5 & \text { Cluster } 6\end{array}$

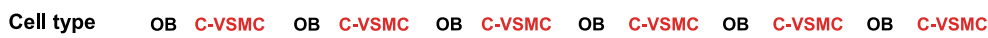

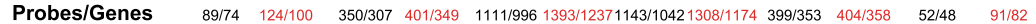

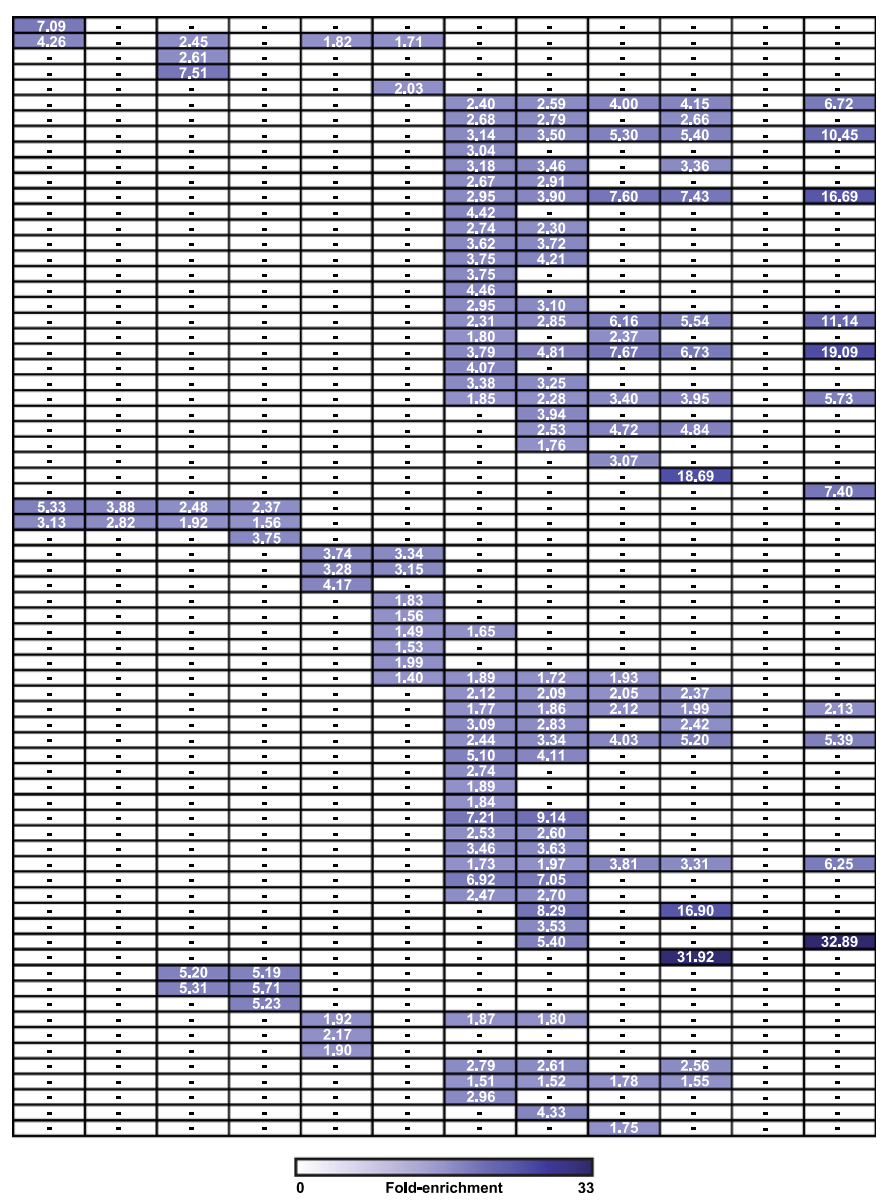

Figure 4 (See legend on next page.) 
(See figure on previous page.)

Figure 4 Clustering of genes with similar expression patterns in C-VSMCs and osteoblasts and respective functional annotation of the clusters. (A) Clusters of genes with similar expression pattern for C-VSMCs and osteoblasts were obtained using $k$-means clustering $(k=6)$. For these analysis only differentially expressed genes were used. Average relative gene expression level $\left(\log _{2}\right.$ fold-change relative to day 0$)$ for all probes within each cluster at the different time points analyzed is shown. (B) Functional annotation for each of the 6 clusters in C-VSMCs and osteoblasts. Only significant (Bonferroni p-value $<0.05$ ) biological process, cellular compartment and molecular function annotations were considered for analysis. Numbers within grid represent fold-enrichment levels of GO-terms in the distinct clusters. The number of probes/genes comprised in each cluster is also indicated.

contrary, GO term such as regulation of osteoblast differentiation and BMP signaling failed to correlate CVSMCs and osteoblasts (Figure 6B and C). In Additional file 7: Figure $\mathrm{S} 2$ the expression pattern of a selection of genes driving the correlation in the GO-term biomineral tissue development and the anti-correlation in the GO- term regulation of BMP signaling is shown. At least LEP (leptin) and SOST (sclerostin), from the correlation and anti-correlation group of genes respectively, could be validated distinct donors (Additional file 1: Figure S3). Moreover, we found good translation between leptin transcript and protein levels, especially for the donor used in the

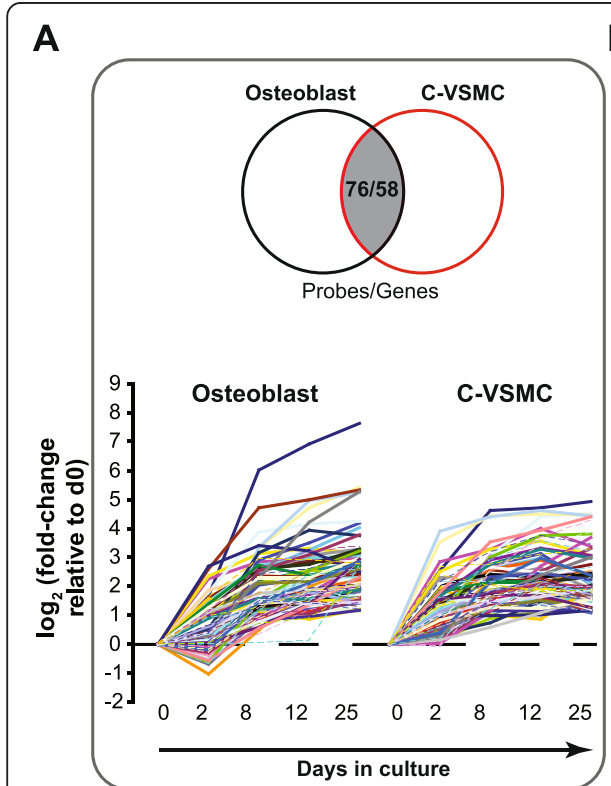

D

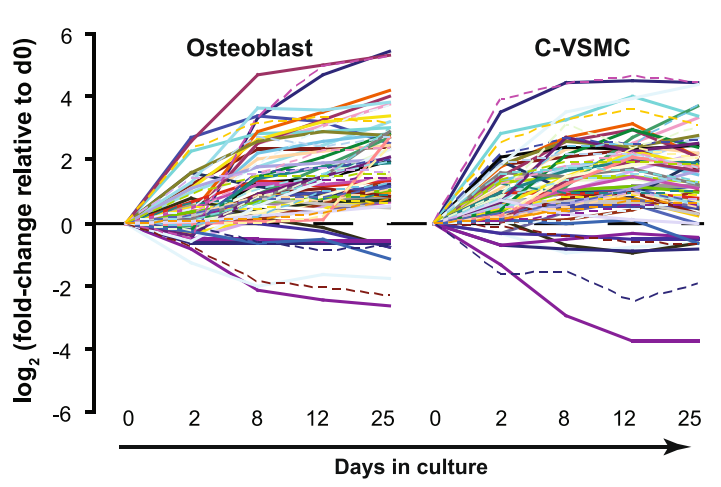

B

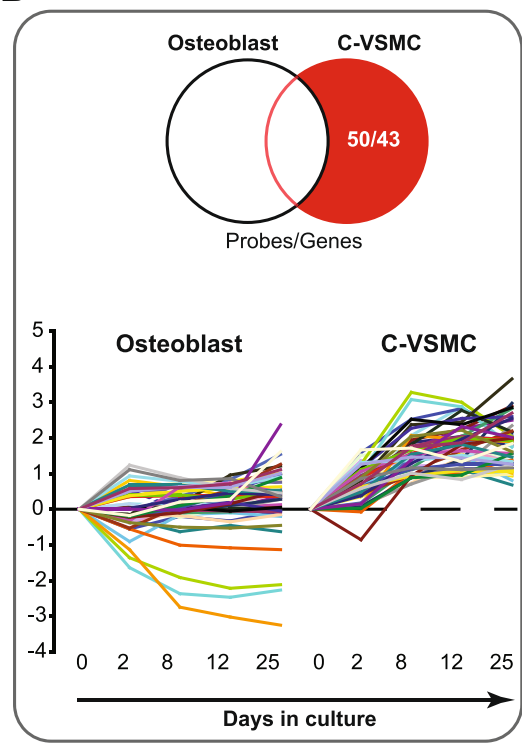

E

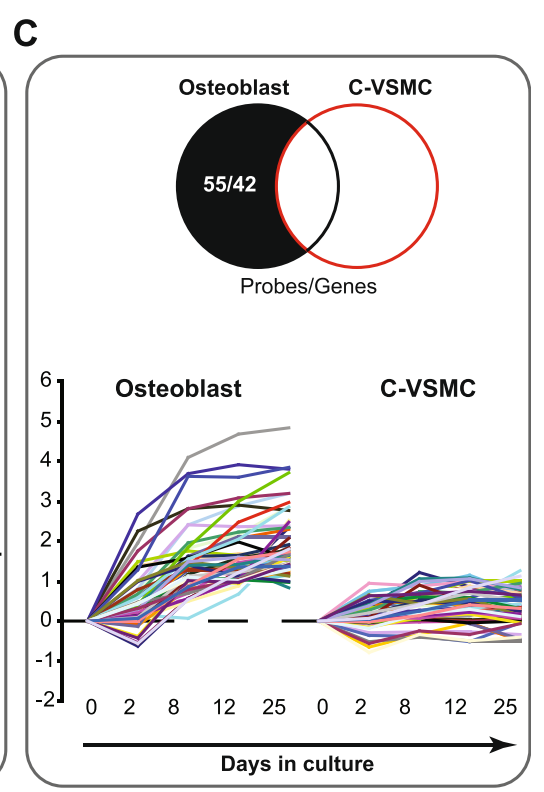

Figure 5 Expression pattern of extracellular region and ECM genes differentially expressed during C-VSMC development and osteoblast differentiation. Temporal expression profile of extracellular region and ECM genes shown in Figure 4 clusters 1 and 2 in (A) both cell types, (B) in C-VSMCs only and (C) in osteoblasts only. Numbers in the Venn diagrams indicate number of probes/genes. (D) Expression profile of ECM probes/genes with identical regulation pattern in C-VSMCs and osteoblasts. A smaller subset of these ECM genes is shown in (E). Expression is plotted as $\log _{2}$ fold-change relative to d0. Each line plotted represents a probe set. Probe/gene identifiers are provided in Additional file 4: Table S2 and Additional file 5: Table S3. 


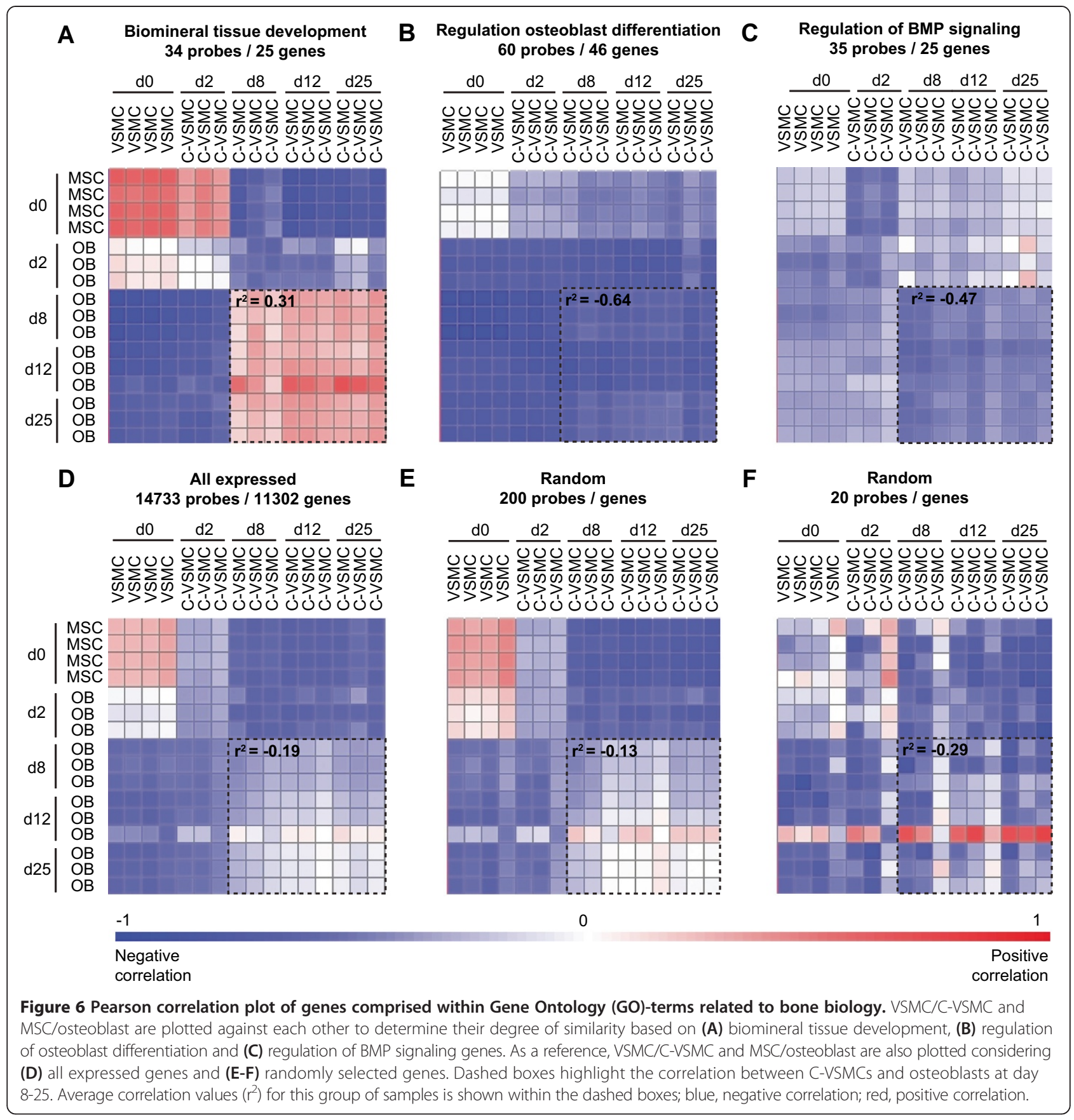

array (Additional file 3: Figure S3). Altogether, our results demonstrate that a specific subset of extracellular genes, including ECM genes, together with genes involved in the regulation of mineralization represent a common denominator between C-VSMCs and osteoblasts.

\section{Discussion}

The current comparative global gene expression profiling analyses of osteoblasts and C-VSMC demonstrate that VSMC under an osteogenic stimulus only partially mimic osteoblasts. Despite the fact that C-VSMCs had an overall transcription profile distinct from osteoblasts, the two cell types regulated identically subsets of ECM and biomineralization genes. These results support the hypothesis that VSMCs require specific osteoblastrelated gene modulation and mechanisms to transdifferentiate into C-VSMCs.

The mechanisms responsible for the transformation of a contractile VSMC into a stiff, mineral surrounded cell are still poorly understood. We demonstrated that the whole VSMCs pool has osteogenic potential and progresses towards ALP + cells when exposed to osteogenic 
stimuli. This indicates that C-VSMCs are not derived from a small and specific vascular cell subpopulation with osteogenic potential, as shown in other vascular calcification models $[10,14]$. The relatively homogenous C-VSMC population (based on ALP activity) observed in our study enabled us to use global gene expression profiles.

Genome-wide gene expression analyses in in vitro models of pathological and physiological mineralization revealed important characteristics of vascular calcifications. C-VSMC development (and osteoblast differentiation) comprised three major phases. The first phase contained VSMC before being triggered to transdifferentiate (day 0; Figure 2). When VSMC were exposed to an osteogenic stimulus, their transcriptional program was quickly altered entering a transient intermediary stage (day 2; Figure 2) after which transcriptional changes became more subtle (day 8-25; Figure 2). We believe that the intermediary phase represents a commitment period responsible for the transition of VSMC into C-VSMCs. In this respect, the clusters of genes identified to be down-regulated (cluster 4-6; Figure 5) were particularly interesting due to their annotation to GO-terms involved in the regulation of cell cycle, cell division and transcription. We believe that the modulation of genes with such functions is possibly associated to the switch of VSMC from proliferative into transdifferentiating cells $[3,4]$, an effect observed in osteoblasts under the influence of glucocorticoids [23,24].

Regarding the comparative transcription profiling, we identified 57 ECM genes identically regulated by CVSMCs and osteoblasts. Their common modulation pattern strongly supports their structural and/or regulatory role in both forms of calcification. On the other hand, ECM genes that did not share identical expression in both cell types are likely to be less crucial for mineral deposition. However, ECM gene data are yet difficult to interpret since little is known about the function of most of the proteins encoded by these genes in matrix mineralization. Genes like DCN, MGP and POSTN constitute exceptions, being known for their crucial role during bone formation and mineralization $[8,25,26]$. MGP for example is a potent inhibitor of calcification both in bone and in the vasculature [8]. These genes represent a strong evidence for the implication of the other ECM genes, with yet unknown relationship to matrix mineralization, in vascular calcifications. This evidence is further substantiated by the fact that several ECM genes (e.g. FBLN5, POSTN, TIMP4) are targets of activin A, a potent inhibitor of ECM mineralization [27]. Recently we have identified over 1200 different proteins present in bone tissue [28]. It is conceivable that ECM proteins act in concert with each other and that the combination of ECM proteins eventually determines the extent of mineralization. It will be a great challenge to identify and characterize these interactions. The current study demonstrating only a limited overlap in ECM gene expression between osteoblasts and C-VSMC will facilitate this challenge by enabling to focus on the selection of overlapping ECM genes. Additional studies focusing on this subset of genes are essential to prove their involvement in biomineralization and during the atherosclerotic process in particular.

Besides ECM, analysis of genes differentially regulated during physiological and pathological calcifications revealed that C-VSMCs share specific genes related to the GO-term biomineral tissue development. ALPL (alkaline phosphatase), GPNMB (glycoprotein nmb), LEP (leptin), PTN (pleiotrophin) and SRGN (serglycin) were among genes within this GO-term that have been already studied in the context of tissue calcifications. ALPL has been shown to be fundamental for mineralization. This pyrophosphatase inactivates the mineralization inhibitory pyrophosphate [29] facilitating not only bone but also vascular calcifications $[17,19]$. Together with ALPL, LEP and GPNMB are genes capable to promote calcifications. LEP is an energy metabolism hormone that enhances mineralization both in bone $[30,31]$ and in vascular tissue [32] while GPNMB, is a glycoprotein implicated in end-stage renal disease (ESRD) a pathological condition associated to ectopic calcifications [33]. Biomineral tissue development genes did not include only genes favouring mineral deposition. SRGN was recently described as an inhibitor of osteoblast mineralization [34]. Despite not described with respect to ectopic mineralizations, the up-regulation of this gene during C-VSMC development might represent a mechanism to protect the vasculature from calcifications similarly to what is described for MGP [15].

Our comparative gene expression profiling constitutes a powerful tool to identify novel targets to control physiological as well as pathological calcifications. Nevertheless, our bioinformatics approach was limited to the identification of genes currently annotated in GO databases as belonging to ECM or involved in biomineralization. We hypothesize that more ECM and biomineralization genes are involved in both forms of calcification but because they are not yet annotated as such they were missed in our analysis. A limitation of our approach is related to the heterogenic response across primary cell sources [35] leading to distinct temporal dynamics during differentiation and mineralization. Overall, results obtained by gene expression array could be confirmed using qPCR within the same donor (Additional file 1: Figure S3). However, analysis of 2 distinct donors revealed less consistent results, likely due to the natural variability of these primary cells and their donors [36]. 
Correlation analysis of bone-related genes expressed during VSMC transdifferentiation showed groups of genes negatively correlated between C-VSMCs and osteoblasts, substantiating the uniqueness of the former cell type. For example, genes of the important osteoblast BMP/TGF- $\beta$ /Activin signaling cascade (e.g. ACVR2A, GREM1, SMAD7) were oppositely regulated by C-VSMCs and osteoblasts. The divergence of these genes in $\mathrm{C}$ VSMCs and osteoblasts supports the concept of cellspecific pathway modulations in both cell types. This is something recently observed in other tissues/cells $[37,38]$ but not yet investigated with respect to medial vascular calcifications and bone. Nevertheless, BMP7 is a gene that appears to corroborate this concept since it is described as promoter of normal osteoblast function $[39,40]$ and capable to prevent atherosclerosis $[41,42]$. More studies are needed to define the exact role of each of these genes and most importantly their cross-talk to other signaling pathways $[43,44]$, like the Wnt signaling of which we have identified genes distinctly modulated between C-VSMCs and osteoblasts (e.g. SOST).

\section{Conclusions}

Altogether, the different analyses support the hypothesis that VSMC transdifferentiate into C-VSMCs keeping their own identity while using mechanisms that osteoblasts use to mineralize. Extracellular (matrix) genes and genes involved in tissue mineralization constitute important common denominators between pathological vascular and physiological bone calcifications. A limitation of our study is that one still has to study heterogeneous MSC and VSMC populations that differ from donor to donor in magnitude of gene expression and temporal dynamics, which relates to differences between donors we observed. Nevertheless the current study provides novel insights into groups of genes and biological processes shared in MSC and VSMC osteogenic differentiation. Our data ought to be tested in a wider pool of primary cell donors in order to further discriminate the consistently regulated genes. Finally, distinct gene regulation between C-VSMC and osteoblasts might be of interest to find cell-specific pathway modulations, opening the possibility to tackle undesired vascular calcifications without disturbing physiologic bone formation and vice versa.

\section{Methods}

\section{Cell culture}

Human bone marrow-derived Mesenchymal Stem Cells (MSCs; PT-2501, Lonza, Walkersville, MD, USA) and Vascular Smooth Muscle Cells (VSMCs; coronary artery smooth muscle cells, CC-2583, Lonza) were cultured as described previously [27]. Briefly, MSCs and VSMCs were expanded in Mesenchymal Stem Cell Basal Medium
(MSCBM, PT-3238, Lonza) supplemented with Mesenchymal Stem Cell Medium SingleQuot Kit (MSCGM, PT-4105, Lonza) and Smooth muscle cell Basal Medium (SmBM, CC-3181, Lonza) supplemented with Smooth muscle Medium-2, SingleQuot Kit (SmGM-2, CC-4149, Lonza) respectively. For induction of MSCs differentiation into osteoblasts (referred also as MSC/osteoblasts) and VSMC development into C-VSMCs (VSMC/C-VSMC), cells were cultured in DMEM medium (GIBCO, Paisley, UK) containing 10\% FCS, penicillin/streptomycin, $1.8 \mathrm{mM}$ $\mathrm{CaCl}_{2}$ (Sigma, St. Louis, MO, USA) and $20 \mathrm{mM}$ HEPES (Sigma), pH 7.5. Additionally, this medium was freshly supplemented with $0.1 \mathrm{mM}$ ascorbic acid (Sigma), $10 \mathrm{mM}$ ß-glycerophosphate (Sigma) and $100 \mathrm{nM}$ dexamethasone (DEX, Sigma). In the present study 2 independent MSC and VSMC donors were used, one for the gene expression array and the other for validation purposes. All analyses were performed on samples collected at the beginning of cell culture (day 0 , before induction of differentiation) and during week 1, 2 and 3 of culture.

\section{Alkaline Phosphatase and protein concentration}

ALP activity was assayed as described elsewhere [45]. Results were corrected for the protein content of the cell lysates. Protein concentration was determined using a BCA kit (Pierce Biotechnology, Rockford, IL, USA) following the manufacturer's instructions.

\section{Flow cytometry analysis of ALP positive cell population}

Cells were washed in PBS, trypsinized and fixed in $2 \%$ PFA for $10 \mathrm{~min}$ at room temperature. Cells were permeabilized in $90 \%$ ice-cold methanol and after re-suspension incubated for $10 \mathrm{~min}$ in blocking solution (PBS/0.5\% BSA). Cells were probed with a primary monoclonal mouse antibody against Alkaline Phosphatase, Tissue Non-Specific (1:100, 1 h; ab17973, Abcam). A goat antimouse IgG R-Phycoerythrin conjugated antibody (1:50, 30 min; M30004-1, Invitrogen, Camarillo, CA, USA) was used as a secondary antibody. Finally, cells were resuspended in PBS and the ALP + population was measured in the PE-A channel (excitation $488 \mathrm{~nm}$ ) using a Becton Dickinson FACS-Canto (BD Biosciences).

\section{RNA isolation and quantification}

Total RNA was isolated using TRIzol (Invitrogen) according to the manufacturer's instructions. An additional step was introduced to remove calcium (derived from ECM). RNA was precipitated by overnight incubation with $4 \mathrm{M} \mathrm{LiCl}$ and $50 \mathrm{mM}$ EDTA at $-20^{\circ} \mathrm{C}$. After precipitation and centrifugation for $30 \mathrm{~min}$ at $14,000 \mathrm{rpm}$ and $4^{\circ} \mathrm{C}$, the RNA pellet was washed four times with $70 \%$ ethanol and dissolved in $\mathrm{H}_{2} \mathrm{O}$. The RNA concentration was determined spectrophotometrically using a NanoDrop ND-2000 (Thermo Scientific, Wilmington, 
DE, USA) and its quality accessed by RNA 6000 Nano assay on a 21000 Bioanalyzer (Agilent Technologies, Santa Clara, CA, USA), both according to the manufacturer's instructions.

\section{Illumina gene chip-based expression}

Gene-chip based expression was performed essentially as recently described [46] using 3 biological replicates per condition with exception for day 0 cultures for which 4 replicates were used. Briefly, $150 \mathrm{ng}$ of RNA were amplified using the Illumina TotalPrep RNA Amplification kit (Ambion, Austin, TX, USA) as recommended by the manufacturer. Single-stranded cDNA was generated using a T7 oligo(dT) primer and was followed by second-strand cDNA synthesis. cDNA was further transcribed in vitro using a T7 RNA polymerase generating biotin-labeled cRNA. After cRNA purification its quality was checked on a Bioanalyzer (Agilent Technologies) and its concentration determined using a NanoDrop (Thermo Scientific). Per array, 750 ng of cRNA were hybridized, washed and detected using the standard Illumina protocol. Slides were scanned on an iScan and analyzed using Genome Studio v2010.1, both from Illumina.

\section{Gene expression data processing}

Gene expression data were processed as described elsewhere [46]. Raw gene expression data were background subtracted using Genome Studio and further processed using the Bioconductor R2.10.0 lumi-package [47]. The data were transformed by variance stabilization and quantile normalized. Probes significantly expressed (Illumina detection $\mathrm{p}$-value $<0.01$ ) in at least 3 samples from VSMC/C-VSMC and MSC/osteoblasts were considered as expressed and used for subsequent analysis, namely multivariate Principal Component Analysis (PCA).

Probes differentially expressed relative to the starting culture condition, i.e. day 0 of culture, were identified using the Bioconductor package 'limma' [48] with adjusted p-values (q-value) to reduce the false discovery rate. Differential expression was considered whenever a probe had a $\log _{2}$ fold-change $>0.5$ (up-regulation) or $<-0.5$ (down-regulation) relative to day 0 and a q-value $<0.001$.

\section{Data analysis: clustering, correlation and functional annotations}

Differentially expressed probes were analyzed by k-means clustering using Gene Pattern (http://www.broadinstitute. org/cancer/software/genepattern/) [49]. Independent clustering analyses were performed for C-VSMCs and osteoblasts. The predictive power of k-means clustering was computed using FOM analysis in MultiExperiment Viewer v4.7 (http://www.tm4.org/) [50]. The maximum number of clusters and iterations was set to 15 and 50 respectively. From the FOM results we opted for 6 clusters $(k=6$; Additional file 3: Figure S1) in both cell types. Differentially expressed probes within each of the groups identified by k-means clustering for C-VSMCs and osteoblasts were analyzed using DAVID Bioinformatics Resources 6.7 (http://david.abcc.ncifcrf.gov/) [51] to obtain a comprehensive description of the over-represented biological processes, cellular compartments and molecular functions. Redundant GO-terms were removed using REViGO (http://revigo.irb.hr/) [52].

In an independent targeted analysis, we matched expressed probes to GO-terms related to bone biology (GO:0031012, ECM; GO:0031214, biomineral tissue development; GO:0030282, bone mineralization; GO:0001503, ossification; GO:0045667, regulation of osteoblast differentiation; GO:0051924, regulation of calcium ion transport; GO:0016462, pyrophosphatase activity; GO:0030510, regulation of BMP signaling pathway). The Illumina probe/ gene symbol information underlying each GO-term was retrieved using the Martview query from the BioMart open source tool version 0.7 (http://www.biomart.org). Genes underlying these GO-terms were subsequently used for correlation analysis essentially as described elsewhere $[28,53]$. Briefly, we calculated the geometric mean of the intensities for each expressed probe set. The level of expression of each probe set was then determined relative to this geometric mean. The expression values were logarithmically transformed (on a base 2-scale) to impute equal weight to gene-expression levels with similar relative distances to the geometric mean. Deviation from the geometric mean was considered as differential gene expression. Similarities and dissimilarities between VSMC/ C-VSMC and MSC/osteoblasts samples were visualized by Pearson's correlation using Omniviz (BioWisdom Inc., version 6.0.1). As a control, similar correlation analysis were performed using randomly selected sets of expressed probes containing similar number of genes as the GO-terms analyzed.

\section{Gene expression validation at mRNA and protein level}

RNA isolation was done as described above. cDNA synthesis and quantitative polymerase chain reaction (qPCR) were carried out as described elsewhere [54] except that the total amount of RNA was quantified spectrophotometrically using NanoDrop technology. Primer and probe sequences $\left(5^{\prime}\right.$ to $\left.3^{\prime}\right)$ were as follows: POSTN forward primer TGT GGA CAG AAA ACG ACT GTG TTA and reverse primer CGA TGC CCA GAG TGC CATA; TGFBI forward primer CTA CAT TTG GAG CCT GGA CA and reverse primer CCG GGT TAT GCT GGT TGTA; LEP forward primer ACA CAC GCA GTC AGT CTC CTC CAA and reverse primer AGG TCA GGA TGG GGT GGA GCC; SOST forward primer GAA TGA TGC CAC GGA AAT CAT and reverse primer CGG ACA CGT CTT TGG TCT CA; TAGLN forward primer GGC TGA AGA 
ACG GCG TGAT and reverse primer GAC CTT CAC CGG CTT GGA; ACTA2 forward primer GAG CGA GGC TAT TCC TTT GTGA and reverse primer ACG TAG CAC AGC TTC TCC TTG AT; PTGS2 forward primer GAA TCA TTC ACC AGG CAA ATTG and reverse primer TCT GTA CTG CGG GTG GAA CA; MGP forward primer CCT GCT CCT TCT CTC CAT TCTG and reverse primer TAG GAT TCC ATA CTT TCA TGA CAT TCG; ADAMTS1 forward primer GGA CAG GTG CAA GCT CAT CTG, reverse primer TCT ACA ACC TTG GGC TGC AAA and FAM/TAMRA probe CAA GCC AAA GGC ATT GGC TAC TTC TTCG; WNT5A forward primer GCT CCG CTC GGA TTC CTC and reverse primer CCA ATG GAC TTC TTC ATG GCG; GREM1 forward primer CGC CGC ACT GAC AGT ATG AG and reverse primer TCT TTT TCC CTT CAG CAG CC. All primers were purchased from Sigma-Aldrich.

For leptin measurements, medium was collected during VSMC/C-VSMC and MSC/osteoblasts cultures. Conditioned medium was collected after $78 \mathrm{~h}$ incubation with the cells. After centrifugation ( $5 \mathrm{~min}, 500 \mathrm{~g}$ ), the medium was stored at $-20^{\circ} \mathrm{C}$ until further analysis. Cell lysates were also collected to analyze the protein content of the corresponding cultures. Leptin was measured in $50 \mu \mathrm{l}$ medium using the Human Leptin DuoSet DY398 ELISA kit (R\&D Systems).

\section{Availability of supporting data}

The gene expression data here analyzed is publicly available and can be retrieved from the Gene Expression Omnibus (GEO) at the National Center for Biotechnology Information (NCBI) under the accession number GSE37558 (data available at http://www.ncbi.nlm.nih.gov/geo/query/acc.cgi? acc $=$ GSE37558).

\section{Additional files}

Additional file 1: Figure S3. Validation of the gene expression data. A selection of genes regulated in VSMC/C-VSMC and MSC/osteoblast was validated using $\mathrm{qPCR}$ in 2 independent donors (Donor $1=$ main donor; Donor 2 = biological replication donor). Leptin expression was also confirmed at the protein level (ELISA) in the conditioned medium from VSMC/C-VSMC and MSC/osteoblast cultures (bottom right panel).

Additional file 2: Table S1. Number of probes differentially expressed in C-VSMCs and osteoblasts. Differential expression was calculated independently for both cell types and relative to their initial time point, day 0 . The 4782 probes regulated were divided in three categories, identical or opposite regulation in the two cell types and cell-specific regulation. Only significantly regulated probes $(q<0.001)$ were considered.

Additional file 3: Figure S1. Figure of merit (FOM) analysis to estimate $k$-means clustering predictive power in genes differentially expressed by C-VSMCs and osteoblasts. The lower the adjusted FOM value (y-axis) the higher the predictive power of the $k$-means algorithm. $k=6$ (dashed lines) was used for both cell types.

Additional file 4: Table S2. List of extracellular region probe/genes present in cluster 1 and 2 of C-VSMCs/osteoblasts, C-VSMCs only and osteoblasts only.
Additional file 5: Table S3. List of ECM probe/genes differentially expressed and identically regulated in C-VSMCs and osteoblasts.

Additional file 6: Table S7. List of biomineral tissue development and BMP signaling probes/genes used for correlation analysis in C-VSMCs and osteoblasts.

Additional file 7: Figure S2. Expression profile of a selection of correlated biomineral tissue development genes and of anti-correlated BMP signaling genes during C-VSMC development and osteoblast differentiation. Expression is plotted as $\log _{2}$ fold-change relative to $\mathrm{d} 0$. Each line plotted represents a probe set. Probe/gene identifiers are provided in Additional file 6: Table S4.

\section{Abbreviations}

ALP: Alkaline phosphatase; BMP: Bone morphogenetic protein; C-VSMC: Calcifying vascular smooth muscle cell; ECM: Extracellular matrix; FOM: Figure of Merit; GO: Gene Ontology; MSC: Mesenchymal stem cell; PCA: Principal component analysis; VSMC: Vascular smooth muscle cell.

\section{Competing interests}

The authors declare that they have no competing interests.

\section{Authors' contributions}

RA carried out the experiments and bioinformatics analyses and has written the concept of the manuscript. ME has made substantial contribution in conceptualizing and designing the experiments and interpretation of the data. JvdP performed the gene expression profiling analyses and was involved in the bioinformatics analyses. JVL substantially contributed to the conception and design of the study and interpretation of the results and gave final approval of the version to be published. All authors read and approved the final manuscript.

\section{Acknowledgements}

This work was supported an ECTS Postdoctoral Fellowship award granted to M. Eijken in 2008, NWO-ZON (contract grant \#91206069) and the Erasmus Medical Center, Rotterdam, The Netherlands. The authors gratefully acknowledge Marijke Koedam and Tanja Strini for the technical assistance provided with cell culture experiments and Bram van der Eerden for support with editing the references.

Received: 6 May 2014 Accepted: 16 October 2014

Published: 7 November 2014

\section{References}

1. Hruska KA, Mathew S, Saab G: Bone morphogenetic proteins in vascular calcification. Circ Res 2005, 97:105-114.

2. Laurent S, Boutouyrie P, Asmar R, Gautier I, Laloux B, Guize L, Ducimetiere P, Benetos A: Aortic stiffness is an independent predictor of all-cause and cardiovascular mortality in hypertensive patients. Hypertension 2001, 37:1236-1241.

3. Steitz SA, Speer MY, Curinga G, Yang HY, Haynes P, Aebersold R, Schinke T, Karsenty G, Giachelli CM: Smooth muscle cell phenotypic transition associated with calcification: upregulation of $\mathrm{Cbfa} 1$ and downregulation of smooth muscle lineage markers. Circ Res 2001, 89:1147-1154.

4. Thyberg J: Differentiated properties and proliferation of arterial smooth muscle cells in culture. Int Rev Cytol 1996, 169:183-265.

5. Chen NX, O'Neill KD, Chen X, Moe SM: Annexin-mediated matrix vesicle calcification in vascular smooth muscle cells. J Bone Miner Res 2008, 23:1798-1805.

6. Reynolds JL, Joannides AJ, Skepper JN, McNair R, Schurgers $L$, Proudfoot $D$, Jahnen-Dechent W, Weissberg PL, Shanahan CM: Human vascular smooth muscle cells undergo vesicle-mediated calcification in response to changes in extracellular calcium and phosphate concentrations: a potential mechanism for accelerated vascular calcification in ESRD. J Am Soc Nephrol 2004, 15:2857-2867.

7. Persy V, D'Haese P: Vascular calcification and bone disease: the calcification paradox. Trends Mol Med 2009, 15:405-416.

8. Luo G, Ducy P, McKee MD, Pinero GJ, Loyer E, Behringer RR, Karsenty G: Spontaneous calcification of arteries and cartilage in mice lacking matrix GLA protein. Nature 1997, 386:78-81. 
9. Rekhter MD, Zhang K, Narayanan AS, Phan S, Schork MA, Gordon D: Type I collagen gene expression in human atherosclerosis. Localization to specific plaque regions. Am J Pathol 1993, 143:1634-1648

10. Bostrom K, Watson KE, Horn S, Wortham C, Herman IM, Demer LL: Bone morphogenetic protein expression in human atherosclerotic lesions. J Clin Invest 1993, 91:1800-1809.

11. Dhore CR, Cleutjens JP, Lutgens E, Cleutjens KB, Geusens PP, Kitslaar PJ, Tordoir JH, Spronk HM, Vermeer C, Daemen MJ: Differential expression of bone matrix regulatory proteins in human atherosclerotic plaques. Arterioscler Thromb Vasc Biol 2001, 21:1998-2003.

12. Schluesener HJ, Meyermann R: Immunolocalization of BMP-6, a novel TGF-beta-related cytokine, in normal and atherosclerotic smooth muscle cells. Atherosclerosis 1995, 113:153-156.

13. Towler DA, Bidder M, Latifi T, Coleman T, Semenkovich CF: Diet-induced diabetes activates an osteogenic gene regulatory program in the aortas of low density lipoprotein receptor-deficient mice. J Biol Chem 1998 273:30427-30434.

14. Watson KE, Bostrom K, Ravindranath R, Lam T, Norton B, Demer LL: TGF-beta 1 and 25-hydroxycholesterol stimulate osteoblast-like vascular cells to calcify. J Clin Invest 1994, 93:2106-2113.

15. Moe SM, Reslerova M, Ketteler M, O'Neill K, Duan D, Koczman J, Westenfeld $\mathrm{R}$, Jahnen-Dechent $\mathrm{W}$, Chen NX: Role of calcification inhibitors in the pathogenesis of vascular calcification in chronic kidney disease (CKD). Kidney Int 2005, 67:2295-2304.

16. Speer MY, McKee MD, Guldberg RE, Liaw L, Yang HY, Tung E, Karsenty G, Giachelli CM: Inactivation of the osteopontin gene enhances vascular calcification of matrix Gla protein-deficient mice: evidence for osteopontin as an inducible inhibitor of vascular calcification in vivo. J Exp Med 2002, 196:1047-1055.

17. Murshed M, Harmey D, Millan JL, McKee MD, Karsenty G: Unique coexpression in osteoblasts of broadly expressed genes accounts for the spatial restriction of ECM mineralization to bone. Genes Dev 2005, 19:1093-1104.

18. Fleisch H, Russell RG, Straumann F: Effect of pyrophosphate on hydroxyapatite and its implications in calcium homeostasis. Nature 1966, 212:901-903.

19. Lomashvili KA, Cobbs S, Hennigar RA, Hardcastle KI, O'Neill WC: Phosphate-induced vascular calcification: role of pyrophosphate and osteopontin. J Am Soc Nephrol 2004, 15:1392-1401.

20. Shanahan CM, Cary NR, Salisbury JR, Proudfoot D, Weissberg PL, Edmonds ME: Medial localization of mineralization-regulating proteins in association with Monckeberg's sclerosis: evidence for smooth muscle cell-mediated vascular calcification. Circulation 1999, 100:2168-2176.

21. Owens GK, Kumar MS, Wamhoff BR: Molecular regulation of vascular smooth muscle cell differentiation in development and disease. Physiol Rev 2004, 84:767-801.

22. Monzack EL, Masters KS: Can valvular interstitial cells become true osteoblasts? A side-by-side comparison. J Heart Valve Dis 2011, 20:449-463.

23. Engelbrecht $Y$, de Wet $H$, Horsch $K$, Langeveldt CR, Hough FS, Hulley PA: Glucocorticoids induce rapid up-regulation of mitogen-activated protein kinase phosphatase-1 and dephosphorylation of extracellular signal-regulated kinase and impair proliferation in human and mouse osteoblast cell lines. Endocrinology 2003, 144:412-422.

24. Smith E, Redman RA, Logg CR, Coetzee GA, Kasahara N, Frenkel B: Glucocorticoids inhibit developmental stage-specific osteoblast cell cycle. Dissociation of cyclin A-cyclin-dependent kinase 2 from E2F4-p130 complexes. J Biol Chem 2000, 275:19992-20001.

25. Horiuchi K, Amizuka N, Takeshita S, Takamatsu H, Katsuura M, Ozawa H, Toyama Y, Bonewald LF, Kudo A: Identification and characterization of a novel protein, periostin, with restricted expression to periosteum and periodontal ligament and increased expression by transforming growth factor beta. J Bone Miner Res 1999, 14:1239-1249.

26. Mochida Y, Parisuthiman D, Pornprasertsuk-Damrongsri S, Atsawasuwan $P$, Sricholpech M, Boskey AL, Yamauchi M: Decorin modulates collagen matrix assembly and mineralization. Matrix Biol 2009, 28:44-52.

27. Eijken M, Swagemakers S, Koedam M, Steenbergen C, Derkx P, Uitterlinden $A G$, van der Spek PJ, Visser JA, de Jong FH, Pols HA, van Leeuwen JP: The activin A-follistatin system: potent regulator of human extracellular matrix mineralization. FASEB J 2007, 21:2949-2960.
28. Alves RD, Eijken M, Swagemakers S, Chiba H, Titulaer MK, Burgers PC, Luider TM, van Leeuwen JP: Proteomic analysis of human osteoblastic cells: relevant proteins and functional categories for differentiation. $J$ Proteome Res 2010, 9:4688-4700.

29. Eaton RH, Moss DW: Kinetic studies on the orthophosphatase and iorganic pyrophosphatase activities of human alkaline phsophatase. Enzymologia 1968, 35:168-178.

30. Pasco JA, Henry MJ, Kotowicz MA, Collier GR, Ball MJ, Ugoni AM, Nicholson GC: Serum leptin levels are associated with bone mass in nonobese women. J Clin Endocrinol Metab 2001, 86:1884-1887.

31. Reseland JE, Syversen U, Bakke I, Qvigstad G, Eide LG, Hjertner O, Gordeladze JO, Drevon CA: Leptin is expressed in and secreted from primary cultures of human osteoblasts and promotes bone mineralization. J Bone Miner Res 2001, 16:1426-1433.

32. Parhami F, Tintut $Y$, Ballard A, Fogelman AM, Demer LL: Leptin enhances the calcification of vascular cells: artery wall as a target of leptin. Circ Res 2001, 88:954-960.

33. Pahl MV, Vaziri ND, Yuan J, Adler SG: Upregulation of monocyte/macrophage HGFIN (Gpnmb/Osteoactivin) expression in end-stage renal disease. Clin J Am Soc Nephrol 2010, 5:56-61.

34. Theocharis AD, Seidel C, Borset M, Dobra K, Baykov V, Labropoulou V, Kanakis I, Dalas E, Karamanos NK, Sundan A, Hjerpe A: Serglycin constitutively secreted by myeloma plasma cells is a potent inhibitor of bone mineralization in vitro. J Biol Chem 2006, 281:35116-35128.

35. Phinney DG, Kopen G, Righter W, Webster S, Tremain N, Prockop DJ: Donor variation in the growth properties and osteogenic potential of human marrow stromal cells. J Cellular Biochem 1999, 75:424-436.

36. Pevsner-Fischer M, Levin S, Zipori D: The origins of mesenchymal stromal cell heterogeneity. Stem Cell Rev 2011, 7:560-568.

37. Fessing MY, Atoyan R, Shander B, Mardaryev AN, Botchkarev W Jr, Poterlowicz K, Peng Y, Efimova T, Botchkarev VA: BMP signaling induces cell-type-specific changes in gene expression programs of human keratinocytes and fibroblasts. J Invest Dermatol 2010, 130:398-404.

38. Morikawa M, Koinuma D, Tsutsumi S, Vasilaki E, Kanki Y, Heldin CH, Aburatani H, Miyazono K: ChIP-seq reveals cell type-specific binding patterns of BMP-specific Smads and a novel binding motif. Nucleic Acids Res 2011, 39:8712-8727

39. Luo G, Hofmann C, Bronckers AL, Sohocki M, Bradley A, Karsenty G: BMP-7 is an inducer of nephrogenesis, and is also required for eye development and skeletal patterning. Genes Dev 1995, 9:2808-2820.

40. Yeh LC, Tsai AD, Lee JC: Osteogenic protein-1 (OP-1, BMP-7) induces osteoblastic cell differentiation of the pluripotent mesenchymal cell line C2C12. J Cell Biochem 2002, 87:292-304.

41. Davies MR, Lund RJ, Hruska KA: BMP-7 is an efficacious treatment of vascular calcification in a murine model of atherosclerosis and chronic renal failure. J Am Soc Nephrol 2003, 14:1559-1567.

42. Dorai H, Vukicevic S, Sampath TK: Bone morphogenetic protein-7 (osteogenic protein-1) inhibits smooth muscle cell proliferation and stimulates the expression of markers that are characteristic of SMC phenotype in vitro. J Cell Physiol 2000, 184:37-45.

43. Guo X, Wang XF: Signaling cross-talk between TGF-beta/BMP and other pathways. Cell Res 2009, 19:71-88.

44. Nakashima A, Katagiri T, Tamura M: Cross-talk between Wnt and bone morphogenetic protein 2 (BMP-2) signaling in differentiation pathway of C2C12 myoblasts. J Biol Chem 2005, 280:37660-37668.

45. Eijken M, Koedam M, van Driel M, Buurman CJ, Pols HA, van Leeuwen JP: The essential role of glucocorticoids for proper human osteoblast differentiation and matrix mineralization. Mol Cell Endocrinol 2006, 248:87-93.

46. Drabek K, van de Peppel J, Eijken M, van Leeuwen JP: GPM6B regulates osteoblast function and induction of mineralization by controlling cytoskeleton and matrix vesicle release. J Bone Miner Res 2011, 26:2045-2051.

47. Du P, Kibbe WA, Lin SM: lumi: a pipeline for processing Illumina microarray. Bioinformatics 2008, 24:1547-1548.

48. Smyth GK: Linear models and empirical bayes methods for assessing differential expression in microarray experiments. Stat Appl Genet Mol Biol 2004, 3:Article3.

49. Reich M, Liefeld T, Gould J, Lerner J, Tamayo P, Mesirov JP: GenePattern 2.0. Nat Genet 2006, 38:500-501.

50. Yeung KY, Haynor DR, Ruzzo WL: Validating clustering for gene expression data. Bioinformatics 2001, 17:309-318. 
51. Dennis G Jr, Sherman BT, Hosack DA, Yang J, Gao W, Lane HC, Lempicki RA: DAVID: Database for Annotation, Visualization, and Integrated Discovery. Genome Biol 2003, 4:P3.

52. Supek F, Bosnjak M, Skunca N, Smuc T: REVIGO summarizes and visualizes long lists of gene ontology terms. PLoS One 2011, 6:e21800.

53. Valk PJ, Verhaak RG, Beijen MA, Erpelinck CA, Barjesteh van Waalwijk van Doorn-Khosrovani S, Boer JM, Beverloo HB, Moorhouse MJ, van der Spek PJ, Lowenberg B, Delwel R: Prognostically useful gene-expression profiles in acute myeloid leukemia. N Engl J Med 2004, 350:1617-1628.

54. Eijken M, Hewison M, Cooper MS, de Jong FH, Chiba H, Stewart PM, Uitterlinden AG, Pols HA, van Leeuwen JP: 11 beta-Hydroxysteroid dehydrogenase expression and glucocorticoid synthesis are directed by a molecular switch during osteoblast differentiation. Mol Endocrinol 2005, 19:621-631.

doi:10.1186/1471-2164-15-965

Cite this article as: Alves et al:: Calcifying vascular smooth muscle cells and osteoblasts: independent cell types exhibiting extracellular matrix and biomineralization-related mimicries. BMC Genomics 2014 15:965.

\section{Submit your next manuscript to BioMed Central and take full advantage of:}

- Convenient online submission

- Thorough peer review

- No space constraints or color figure charges

- Immediate publication on acceptance

- Inclusion in PubMed, CAS, Scopus and Google Scholar

- Research which is freely available for redistribution 